Научная статья

УДК 330.43

DOI 10.18101/2304-4446-2021-4-100-106

\title{
ЭКОНОМЕТРИЧЕСКОЕ МОДЕЛИРОВАНИЕ ВЗАИМОСВЯЗИ МЕЖДУ ПОКАЗАТЕЛЯМИ ЭКОНОМИЧЕСКОГО РОСТА И НЕРАВНОМЕРНОСТИ ЭКОНОМИЧЕСКОГО РАЗВИТИЯ
}

\author{
(C) Чимитдоржиева Екатерина Цыренжабовна \\ кандидат экономических наук, \\ Бурятский государственный университет имени Доржи Банзарова \\ Россия, 670000, г. Улан-Удэ, ул. Смолина, 24а \\ katrin_c@mail.ru
}

\begin{abstract}
Аннотация. В данной статье рассматривается проблема взаимосвязи экономического роста и неравномерности экономического развития на региональном уровне. В качестве показателя оценки экономического роста выступили темпы роста валового регионального продукта (ВРП). Оценка неравномерности экономического развития осуществлялась с помощь коэффициентов вариации, рассчитанных по показателям муниципальных районов региона. Дальнейшее исследование связано с получением статистически значимых уравнений связи между темпами роста ВРП и коэффициентами вариации. В силу того, что исходными данными для построения уравнений регрессии являлись временные ряды, то для получения адекватных зависимостей возникла необходимость в использовании теории коинтеграции. Применение данного подхода позволило говорить о наличии коинтеграции между коэффициентом вариации, рассчитанным по показателю «Инвестиции в основной капитал», и темпами роста ВРП. Скорость коррекции коэффициента неравномерности существенно выше, чем аналогичный показатель для темпов роста ВРП.
\end{abstract}

Ключевые слова: неравномерность экономического развития, экономический рост, коинтеграция.

\section{Для цитирования}

Чимитдоржиева Е. Ц. Эконометрическое моделирование взаимосвязи между показателями экономического роста и неравномерности экономического развития // Вестник Бурятского государственного университета. Экономика и менеджмент. 2021. № 4. С. 100-106.

\section{Введение}

Проблемам экономического роста и неравномерности развития посвящено большое количество научных трудов. Как правило, исследования направлены на определение сущности понятия «экономический рост» и последующий анализ факторов, которые как способствуют экономическому росту, так и сдерживают его $[3,5]$.

С неравномерностью экономического развития ситуация схожа. Большинство ученых, рассматривающих данную проблематику, пытаются определить содержание этого понятия и систематизировать большое количество факторов, начиная от географических, заканчивая субъективными (нерациональность политикоэкономических решений), которые вызывают данный эффект [9]. Несмотря на это, проблема до сих пор является актуальной. 
E. Ц. Чимитдоржсиева. Эконометрическое моделирование взаимосвязи между показателями экономического роста и неравномерности ...

В таком разнообразии подходов и мнений особое место занимают труды, посвященные взаимосвязи этих двух проблем $[2,10]$. Есть мнение, что развитие неотделимо от неравенства, порождая его и им же порождаясь или усиливаясь [8]. С другой стороны, исследование Барро и Сала-и-Мартина показывают, что развитие мирового экономического хозяйства привело к значительному снижению уровня бедности. Так, за период с 1980 по 2000 г. неравенство между богатыми и бедными фактически несколько сократилось [10].

Таким образом, существование различных точек зрения свидетельствует о том, что эта проблематика является достаточно актуальной, требующей пристального внимания.

Цель исследования заключается в построении эконометрической модели, отражающей связь между показателями неравномерности экономического развития и показателями экономического роста.

\section{Методология и результаты исследования}

Описание неравномерности экономического развития происходит с использованием различных терминов. Наиболее часто применяются понятия «дисбаланс», «поляризация», «плотность», «асимметрия», «концентрация» и т. д. Оценка неравномерности может производиться с использованием статистических показателей дифференциации и концентрации (дисперсии, среднего квадратического отклонения, коэффициента вариации, коэффициента неравномерности, коэффициента Гатева, индекса Джини, индекса Тейла и т. д.), с использованием процедуры ранжирования по некоторому интегральному критерию, отражающему уровень экономического развития, а также с применением многомерных статистических методов классификации [7]. Важное место занимают исследования динамических особенностей развития неравномерности во взаимосвязи с экономическим ростом, которые сформировались в теорию ковергенции и дивергенции $[4,11,2]$.

В исследовании неоднородность экономического развития региона оценивалась на уровне муниципальных районов. В качестве основных показателей экономического развития муниципальных образований Республики Бурятия использовались:

$\checkmark$ объем отгруженных товаров собственного производства, выполненных работ и услуг собственными силами по чистым видам экономической деятельности (тыс. р.);

$\checkmark$ объем инвестиций в основной капитал (тыс. p.);

$\checkmark$ объем платных услуг населению (тыс. р.);

$\checkmark$ объем производства продукции сельского хозяйства (тыс. р.).

Для оценки неравномерности экономического развития применялся коэффициент вариации. Для каждого показателя экономического развития, перечисленного выше, был рассчитан коэффициент вариации.

На рисунке 1 представлены индикаторы неравномерности, рассчитанные по экономическим показателям муниципальных районов Республики Бурятия. Динамика коэффициента вариации, оцениваемого по показателю «Отгружено товаров собственного производства», в целом отражает снижение неравномерности между муниципальными районами. Среднегодовой темп роста этого индикатора неравномерности составляет 99,55\%. 
Коэффициент вариации, оцениваемый по показателю «Объем платных услуг населению» не имеет ярко выраженной тенденции. Среднегодовой темп роста коэффициента за рассматриваемый период составил 99,65\%. Увеличение неравномерности в 2009 г. связано с ростом платных услуг населению в Джидинском и Муйском районах.

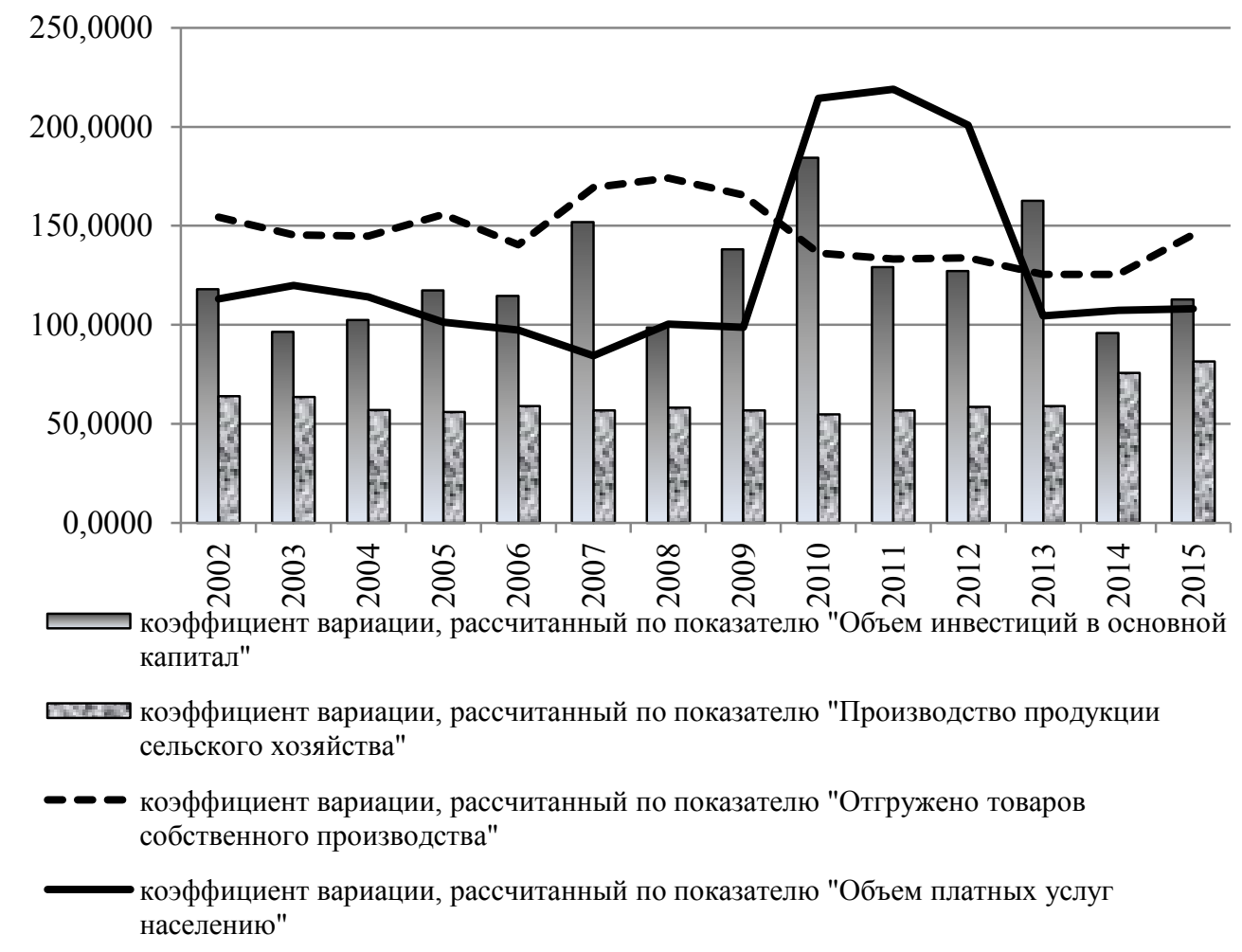

Рис. 1. Показатели неравномерности экономического развития с 2002 по 2015 г., в процентах

Среднегодовой темп роста неравномерности между муниципальными образованиями по показателю «Производство продукции сельского хозяйства» составляет 99,66\%. Визуальный анализ графика не позволяет сделать выводы о наличии тенденции в динамике показателя неравномерности.

Наибольшей волатильностью обладает коэффициент вариации, оцениваемый по показателю «Инвестиции в основной капитал». При этом среднегодовой темп составил 101,90\%, что несколько выше по сравнению со среднегодовыми темпами других показателей.

Период с 2016 по 2018 г. характеризуется отсутствием данных по многим показателям муниципальной статистики, поэтому было принято решение в качестве анализируемого периода выбрать временной промежуток с 2002 по 2015 г.

Оценка экономического роста осуществлялась с использованием темпов роста валового регионального продукта (рис. 2). 
E. Ц. Чимитдоржсиева. Эконометрическое моделирование взаимосвязи между показателями экономического роста и неравномерности ...

Анализ графика позволяет говорить о наличии тенденции к снижению темпов роста ВРП. Наибольшее падение пришлось на 2009 г. и вызвано кризисными явлениями в мировой экономике.

Для оценки связи между параметрами экономического роста и неравномерности развития нами были рассчитаны коэффициенты корреляции (табл. 1).

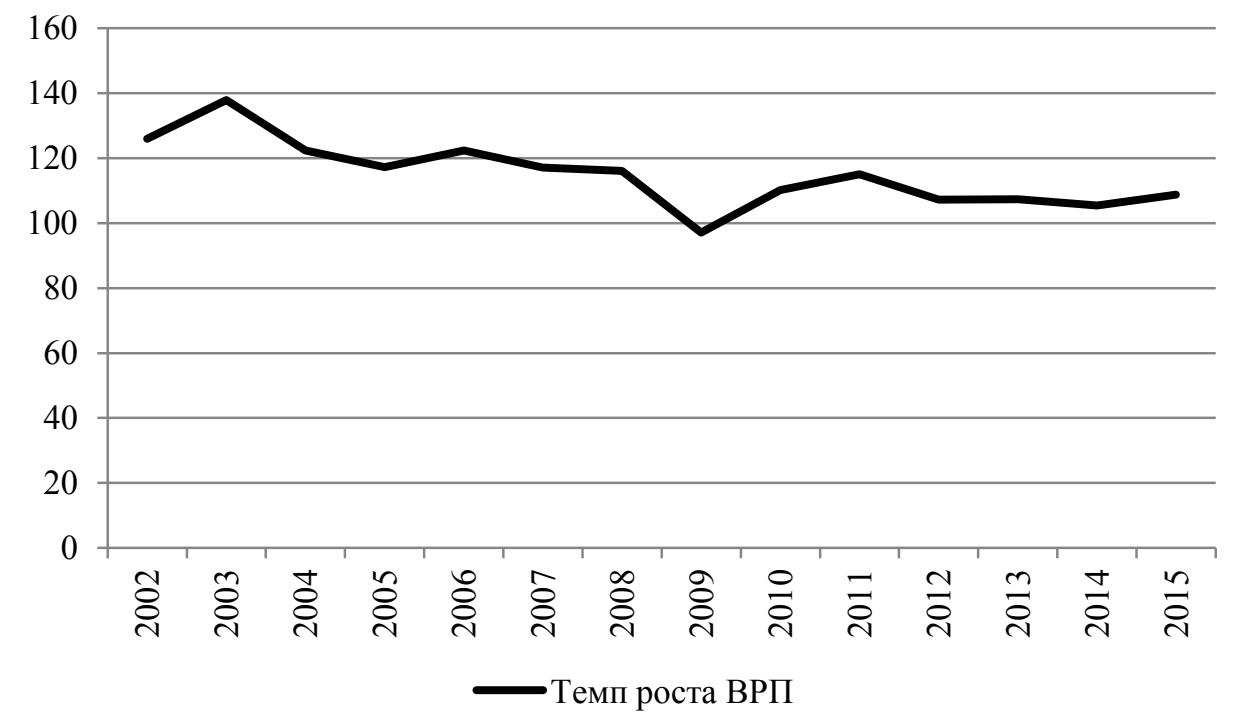

Рис. 2. Темпы роста ВРП с 2002 г. по 2015 г., в процентах

Таблица 1

Корреляция между показателями неравномерности экономического развития и экономического роста

\begin{tabular}{|l|c|c|}
\hline \multicolumn{1}{|c|}{ Показатель } & $\begin{array}{c}\text { Парный коэффициент } \\
\text { корреляции между } \\
\text { показателем неравно- } \\
\text { мерности и темпом } \\
\text { роста ВРП }\end{array}$ & t-статистика \\
\hline $\begin{array}{l}\text { Коэффициент вариации, оцениваемый по } \\
\text { показателю «Отгружено товаров собствен- } \\
\text { ного производства, выполнено работ и услуг } \\
\text { собстенными силами» }\end{array}$ & 0,135 & 0,471 \\
\hline $\begin{array}{l}\text { Коэффициент вариации, оцениваемый по } \\
\text { показателю «Объем платных услуг населе- } \\
\text { нию» }\end{array}$ & $-0,132$ & $-0,462$ \\
\hline $\begin{array}{l}\text { Коэффициент вариации, оцениваемый по } \\
\text { показателю «Инвестиции в основной капи- } \\
\text { тал» }\end{array}$ & $-0,407$ & $-1,544$ \\
\hline $\begin{array}{l}\text { Коэффициент вариации, оцениваемый по } \\
\text { показателю «Производство продукции сель- } \\
\text { ского хозяйства» }\end{array}$ & $-0,099$ & $-0,347$ \\
\hline
\end{tabular}


В целом сильной линейной связи между показателями не обнаружено. Статистически значимым по $t$-критерию на $20 \%$ уровне значимости является коэффициент корреляции, рассчитанный между показателем неравномерности в сфере инвестиций и темпом роста ВРП. Отрицательность коэффициента корреляции свидетельствует о том, что при ускорении экономического роста неравномерность развития снижается, а при замедлении, наоборот, увеличивается.

Так как исходные данные представляют собой временные ряды, то возникает необходимость в исследовании коинтеграционных процессов [1]. Как правило, временные ряды, составленные по экономическим показателям, имеют тренд, следовательно, являются нестационарными. В результате построения уравнения регрессии по таким временным рядам наблюдается высокое значение коэффициента вариации и коэффициента корреляции. Уравнение является статистически значимым по $F$-критерию, но статистика Дарбина - Уотсона стремится к нулю [6]. Однако существование уравнения регрессии с подобными характеристиками еще не означает наличие связи между переменными, возможны случаи ложной регрессии. Наличие тренда в динамике экономических показателей может привести к неверным выводам относительно зависимости между временными рядами. В связи с этим есть необходимость в использовании теста на наличие коинтеграции между переменными.

Тестирование временных рядов на наличие коинтеграции осуществлялось с помощью подхода Ингла-Грейнджера (табл. 2).

Таблица 2

Тест Ингла-Грейнджера на коинтеграцию с темпом роста ВРП (тест без константы)

\begin{tabular}{|l|c|c|}
\hline \multicolumn{1}{|c|}{ Показатель } & Статистика & $p$-значение \\
\hline $\begin{array}{l}\text { Коэффициент вариации, оцениваемый по показате- } \\
\text { лю «Отгружено товаров собственного производства, } \\
\text { выполнено работ и услуг собственными силами» }\end{array}$ & $-2,36389$ & 0,1446 \\
\hline $\begin{array}{l}\text { Коэффициент вариации, оцениваемый по показате- } \\
\text { лю «Объем платных услуг населению» }\end{array}$ & $-1,58586$ & 0,4165 \\
\hline $\begin{array}{l}\text { Коэффициент вариации, оцениваемый по показате- } \\
\text { лю «Инвестиции в основной капитал» }\end{array}$ & $-3,3926$ & 0,04322 \\
\hline $\begin{array}{l}\text { Коэффициент вариации, оцениваемый по показате- } \\
\text { лю «Производство продукции сельского хозяйства» }\end{array}$ & $-3,27067$ & 0,03098 \\
\hline
\end{tabular}

По данным таблицы 2 существование коинтеграции не отвергается на уровне значимости 5\% между коэффициентом вариации, оцениваемым по показателю «Инвестиции в основной капитал» $\left(K V_{\text {invest }}\right)$ и темпами роста BPП (TR_VRP), a также коэффициентом вариации, который был рассчитан по показателю «Производство продукции сельского хозяйства» и темпом роста ВРП. Результаты построения модели коррекции ошибок (VECM) для первого многомерного временного ряда представлены в таблице 3. 
E. Ц. Чимитдоржсиева. Эконометрическое моделирование взаимосвязи между показателями экономического роста и неравномерности ...

Таблица 3

Модель многомерного временного ряда

\begin{tabular}{|l|l|c|}
\hline \multicolumn{1}{|c|}{$\begin{array}{c}\text { Элемент многомерного } \\
\text { временного ряда }\end{array}$} & \multicolumn{1}{|c|}{$\begin{array}{c}\text { Коинтеграционное } \\
\text { уравнение }\end{array}$} & $\begin{array}{c}\text { Корректирующий } \\
\text { вектор }\end{array}$ \\
\hline $\begin{array}{l}\text { Коэффициент вариации, } \\
\text { оцениваемый по показате- } \\
\text { лю «Инвестиции в основ- } \\
\text { ной капитал», темп роста }\end{array}$ & $\begin{array}{l}K V_{\text {invest }}=-1,2511 \cdot \text { TR_VRP } \\
(0,51038)\end{array}$ & $\begin{array}{c}K V_{-} \text {invest }-1,2691 \\
\text { TR_VRP 0,0704 }\end{array}$ \\
ВРП & & \\
\hline
\end{tabular}

Построение модели коррекции ошибок для второго многомерного ряда показало низкое качество модели. В остатках модели наблюдаются автокорреляция и гетероскедастичность. Долгосрочное соотношение между неравномерностью инвестиций и темпами экономического роста также подтверждает обратно пропорциональную связь между показателями. Корректирующий вектор, отражающий краткосрочную реакцию переменных на отклонение от долгосрочной тенденции, позволяет говорить о том, что скорость коррекции коэффициента вариации существенно выше, чем темпов роста ВРП.

\section{Выводы}

Согласно проведенному исследованию неравномерность экономического развития на муниципальном уровне региона имеет определенную взаимосвязь с экономическим ростом. Статистически значимым является коэффициент корреляции между показателем вариации, оценивающим неравномерность в области инвестиций, и темпами роста ВРП. Причем, характер связи обратно пропорциональный. Увеличение темпов экономического роста ведет к снижению неравномерности на муниципальном уровне.

\section{Литература}

1. Айвазян С. А., Фантаццини Д. Эконометрика-2: продвинутый курс с приложениями в финансах: учебник. Москва: Магистр: Инфра-М, 2014. 944 с.

2. Глущенко К. П. Метода анализа межрегионального неравенства по доходам / К. П. Глущенко // Регион: экономика и социология. 2010. №1. С. 54-87.

3. Горюнова Н. Н. Экономический рост как фактор экономического развития / Н. Н. Горюнова // Теория и практика общественного развития. 2013. № 7. С. 183-185.

4. Иванова В. И. Региональная конвергенция доходов населения: пространственный анализ // Пространственная экономика. 2014. № 4. С. 100-119.

5. Лаврентьев А. С., Криничанский К. В. Экономический рост регионов: анализ на основе комплементарных факторов // Вестник ЮУр ГУ. Серия. Экономика и менеджмент. 2020. Т. 14, №2. С. 28-36.

6. Подкорытова О. А., Соколов М. В. Анализ временных рядов: учебное пособие для бакалавриата и магистратуры. 2-е изд., перераб. и доп. Москва: Юрайт, 2018. 268 с.

7. Прикладная статистика: классификация и снижение размерности: справ. изд. / С. А. Айвазян, В. М. Бухштабер, И. С. Енюков, Л. Д. Мешалкин; под ред. С. А. Айвазяна. Москва: Финансы и статистика, 1989. 607 с.

8. Трейвиш А. И. Неравномерность и структурное разнообразоие пространственного развития экономики как научная проблема и российская реальность // Пространственная экономика. 2019. Т. 15, №4. С. 13-35. 
9. Фенин К. В. Факторы неравномерного территориального развития российской экономики // Глобальные проблемы модернизации национальной экономики: материалы IX Международной научно-практической конференции (13 апреля 2020 г., г. Тамбов). Тамбов: Державинский, 2020. С. 116-129.

10. Barro R. J., Sala-i-Martin X. Economic growth. 2nd ed. Cambridge, MA; London: MIT Press, 2004. $672 \mathrm{p}$.

11. Barro R. J., Sala-i-Martin X. Regional Growth and Migration: A Japan - United States Comparision // Journal of Japanese and International Economies. 1992. Vol. 6. Issue 4. Pp. 312-346.

Статья поступила в редакцию 12.09.2021; одобрена после рецензирования 29.10.2021; принята к публикации 01.11.2021

\title{
ECONOMETRIC MODELING OF CORRELATION BETWEEN INDICATORS OF ECONOMIC GROWTH AND UNEVEN ECONOMIC DEVELOPMENT
}

\author{
Ekaterina Ts. Chimitdorzhieva \\ Cand. Sci. (Econ.), \\ Dorzhi Banzarov Buryat State University \\ 24a Smolina St., Ulan-Ude 670000, Russia \\ katrin_c@mail.ru
}

Abstract. The article considers the problem of correlation between economic growth and uneven economic development at the regional level. The gross regional product (GRP) growth rate was used as an indicator for assessing the economic growth. We assessed the unevenness of the economic development using the coefficients of variation, calculated according to the indicators of the municipal districts of the region. Then we obtaining statistically significant equations of the correlation between the GRP growth rate and the coefficients of variation. Since the initial data for the construction of regression equations were time series, in order to obtain adequate dependences we used the theory of cointegration. This approach made it possible to identify the cointegration between the coefficient of variation calculated according to the indicator "Fixed Investment", and the GRP growth rate. The rate of correction of the unevenness coefficient is significantly higher than the analogous indicator for the GRP growth rate.

Keywords: uneven economic development, economic growth, cointegration.

\section{For citation}

Chimitdorzhieva E. Ts. Econometric Modeling of Correlation Between Indicators of Economic Growth and Uneven Economic Development. Bulletin of Buryat State University. Economy and Management. 2021; 4: 100-106 (In Russ.).

The article was submitted 12.09.2021; approved after reviewing 29.10.2021; accepted for publication 01.11.2021. 